\title{
Reposição de cães em área endêmica para leishmaniose visceral
}

\section{Dog replacement in an area endemic for visceral leishmaniasis}

\author{
Andréa Maria Andrade', Luzia Helena Queiroz ${ }^{2}$, Gilson Ricardo Nunes ${ }^{1}$, \\ Sílvia Helena Venturoli Perri² e Cáris Maroni Nunes²
}

\begin{abstract}
RESUMO
Esse trabalho objetivou estimar a reposição de cães em área endêmica para leishmaniose visceral, onde a eutanásia de animais soropositivos é indicada como medida de controle, e avaliar os motivos que levaram a aquisição ou não de novos animais. Houve a reposição em $44,5 \%$ dos casos, principalmente devido à necessidade de companbia ou guarda. O principal motivo para a não-reposição foi o temor da leishmaniose visceral.
\end{abstract}

Palavras-chaves: Leishmaniose visceral. Reposição canina. População canina.

\section{ABSTRACT}

This study aimed to estimate the dog replacement rate in an area endemic for visceral leishmaniasis, in which slaughter of seropositive animals was indicated as a control measure, and to evaluate the reasons why new animals were or were not acquired. The animals were replaced in $44.5 \%$ of the cases, and this was done mainly because of the need for a companion or guard dog. The main reason for not replacing the dog was fear of visceral leishmaniasis.

Key-words: Visceral leishmaniasis. Canine replacement. Canine population.

A leishmaniose visceral (LV) é uma zoonose transmitida por vetor, de importância mundial que envolve os cães como reservatórios. No Brasil, a $\mathrm{LV}$ atinge 19 estados, especialmente na região Nordeste, onde se concentram mais de $90 \%$ dos casos humanos da doença ${ }^{6}$. Há focos também nas regiões Norte, Sudeste e Centro-Oeste, sendo que nas últimas décadas tem se observado um crescente aumento de incidência, com uma média anual de 3.500 casos em humanos ${ }^{2}$.

Em Araçatuba, município localizado ao noroeste do Estado de São Paulo, a LV foi identificada pela primeira vez em 1998 em cães e, em 1999, em humanos ${ }^{4}$. Em um período de sete anos (1999 a 2005) infectou 200 pessoas com 20 óbitos ${ }^{9}$. A prevalência média da doença em cães tem sido $9 \%$, com maior ocorrência nos bairros periféricos ${ }^{1}$. Para 0 controle desta zoonose 0 município segue, desde o início da endemia, as recomendações da Secretaria de Estado da Saúde do Estado de São Paulo que compreendem o diagnóstico precoce e o tratamento adequado dos casos humanos, o emprego de inseticidas de ação residual e medidas de saneamento do meio doméstico para a redução da densidade vetorial e a identificação e eliminação do reservatório doméstico, fonte de infecção para o vetor ${ }^{8}$. Devido a essas recomendações e ao temor da população pela LV, 41.774 cães foram sacrificados no Centro de Controle de Zoonoses (CCZ) do município entre os anos de 1999 a 2004¹. Apesar desta alta taxa de eliminação de cães, a população canina apresentou apenas uma pequena redução de 34.332 cães em 1999, para 31.793 em $2004^{1}$.

Esse trabalho teve como objetivo avaliar a reposição de animais em residências que tiveram cães sacrificados pelo CCZ de Araçatuba bem como avaliar os motivos que levaram a aquisição ou não de novos animais. Para tanto, foram entrevistados, pelo telefone, os proprietários de cães sacrificados pelo CCZ de Araçatuba no período de janeiro a junho de 2004. Os entrevistados foram questionados sobre a substituição ou não do cão sacrificado, pela quantidade e espécies de animais adotados e as razões que os levaram ou não a adquirir novos animais. Esses telefonemas foram dados de janeiro a junho de 2005, exatamente um ano após a entrega dos animais. Os inquéritos realizados por telefone, apesar de serem práticos e de rápida execução,

\footnotetext{
1. Centro de Controle de Zoonoses, Secretaria de Saúde e Higiene Pública, Prefeitura Municipal de Araçatuba, Araçatuba, SP. 2. UNESP - Universidade Estadual Paulista, Curso de Medicina Veterinária, Departamento de Apoio, Produção e Saúde Animal, Araçatuba, SP.

Endereço para correspondência: Dra. Cáris Maroni Nunes. Rua Clóvis Pestana 793, Jardim D. Amélia, 16050-680 Araçatuba, SP.

Tel: 5518 3636-1365; Fax: 5518 3636-1352

e-mail: caris@fmva.unesp.br

Recebido para publicação em: 26/05/2006

Aceito em: 24/08/2007
} 
apresentam o inconveniente de não contemplarem todos os indivíduos de uma população, excluindo geralmente aqueles de menor poder aquisitivo. Ainda que este seja um viés da presente pesquisa, julgou-se importante tal avaliação considerando-se que $52 \%(1.179 / 2.283)$ das fichas eram de proprietários que tinham a chance de serem entrevistados.

No período estudado, 2.283 munícipes entregaram cães para sacrifício. Destes, 1.104 não tinham telefones registrados em listas telefônicas locais. Dos munícipes com telefone, 647 foram entrevistados e 44,5\% (288/647) deles repuseram o animal sacrificado. A preferência pela adoção de outro cão foi observada em 87,5\% (252/288) dos casos, por gato em 7,3\% (21/288) dos casos e em 5,2\% (15/288) das vezes, a opção foi pela reposição por cão e gato. Dos proprietários que substituíram os animais por outros cães, 81\% (204/252) o fizeram com apenas um animal, $15,5 \%$ (39/252) com dois e 3,6\% (9/252) por 3 ou mais cães.

As justificativas mais comuns para a reposição do animal morto foram companhia (60\%) e guarda (33\%). Os entrevistados que não adquiriram novos animais alegaram temor da LV (41\%), falta de espaço na residência (13\%), o custo inerente à criação de cães (13\%), falta de oportunidade (11\%), não gostar de animais (10\%), já terem reposto mas o animal já havia morrido (10\%), entre outras causas.

Os resultados revelam que, no momento da entrevista, quase metade (45\%) da população canina avaliada havia sido substituída, não tendo sido adicionado a este percentual os cães repostos que morreram antes da entrevista e aqueles exproprietários que estavam à procura de um novo animal. Além disto, 19\% das reposições foram feitas com mais de um animal, contribuindo para que o impacto da reposição canina seja ainda maior após um ano.

Das pessoas que repuseram os cães, a maioria o fez por animais da mesma espécie, mostrando a preferência dos entrevistados por este animal. Embora o município esteja vivenciando uma endemia de LV e parte dos seus animais tenha sido sacrificada por este motivo, os ex-proprietários não se privam do direito de terem cães como animal de estimação e guarda, comprometendo a eficiência da eutanásia de cães positivos como medida de controle da LV.

Dye ${ }^{3}$ quando desenvolveu modelo matemático para avaliar as medidas de controle da LV, já salientou que uma parcela de cães sacrificados é reposta pela população, na tentativa de compensar a perda de seu animal de estimação, o que influencia negativamente o controle através da eutanásia de cães positivos.

Moreira Jr e cols ${ }^{7}$ em estudo longitudinal sobre a dinâmica populacional em área endêmica para LV (Jequié-BA) também concluem que a eutanásia de cães positivos, mesmo quando realizada com eficiência, não reduz a incidência da leishmaniose visceral canina (LVC).

Além disto, a renovação torna a população canina mais jovem ${ }^{5}$ e as implicações epidemiológicas deste fato incluem maior suscetibilidade a diferentes doenças, maior prolificidade e baixa resposta imunológica frente a diversas vacinas contra importantes enfermidades, como por exemplo, a raiva ${ }^{10}$. Portanto, a eutanásia que deveria servir como instrumento para diminuir a ocorrência da LVC, parece influenciar mais na estrutura da população canina do que no seu tamanho, e as implicações epidemiológicas resultantes de uma população canina mais jovem podem ser graves. Assim, programas de posse responsável, com enfoque na qualidade de vida dos animais, parecem mais interessantes que meios de controle populacional em áreas endêmicas para leishmaniose visceral.

\section{REFERÊNCIAS}

1. Andrade AM. Dinâmica populacional canina na área urbana do município de Araçatuba, SP, no período de 1994 a 2004. Dissertação de Mestrado. Universidade Estadual Paulista, Araçatuba, 2006.

2. Carmo EH. Leishmaniose Visceral no Brasil: situação atual, principais aspectos epidemiológicos, clínicos e medidas de controle. Revista da Sociedade Brasileira de Medicina Tropical 35 (supl III): 41-45, 2002.

3. Dye C. The logic of visceral leishmaniasis control. American Journal of Tropical Medicine and Hygiene 55:125-130, 1996.

4. Galimbertti MZ, Katz G, Camargo-Neves VLF, Rodas LAC, Casanova C, Costa IP, Araújo MFL, Taniguchi HH, Barbosa JAR, Barbosa JE, Tolezano JE, Pinto PLS. Leishmaniose Visceral Americana no Estado de São Paulo. Revista da Sociedade Brasileira de Medicina Tropical 32 (supl I): 217-218, 1999.

5. Lima Júnior AD. Caracterização da população canina para o controle da raiva e outros problemas de saúde pública. Ciência Veterinária Tropical 2:65-78, 1999.

6. Ministério da Saúde. Taxa de incidência da leishmaniose visceral, 1990-2003. Rede Interagencial para a saúde. Disponível em: www.tabnet.datasus.gov.br/ cgi/tabcgi.exe?idb2004/d0205.def. Acessado em 19/05/2006.

7. Moreira Jr ED, Souza VMM, Sreenivasan M, Nascimento EG, Carvalho LP. Assessment of an optimezed dog-culling program in the dynamics of canine Leishmania transmission. Veterinary Parasitology 122:245-252, 2004.

8. Secretaria de Estado da Saúde do Estado de São Paulo. Centro de Vigilância Epidemiológica "Prof. Alexandre Vranjac", Superintendência de Controle de Endemias, Instituto Adolfo Lutz, coordenação do Programa Estadual de DST/AIDS, Instituto Pasteur. II Informe técnico leishmaniose visceral americana, 2003.

9. Secretaria de Estado da Saúde do Estado de São Paulo. Centro de Vigilância Epidemiológica "Prof. Alexandre Vranjac". Leishmaniose visceral americana humana Casos autóctones e óbitos de leishmaniose visceral americana, segundo município de residência, 1999-2005. Disponível em: www.cve.saude.sp.gov. $\mathrm{br} / \mathrm{htm} /$ zoo/lvah_auto9904.htm. Acessado em 19/05/2006.

10. Silva LHQ. Produção de anticorpos e determinação da resistência adquirida à raiva canina. Tese de Doutorado. Instituto de Ciências Biomédicas, Universidade de São Paulo, São Paulo, 1999. 